\title{
LIX. Description of a hydro-pneumatic blow-pipe for the use of chemists, enamellers, assayers, and glass-blowers
}

\author{
Mr. John Tilley
}

To cite this article: Mr. John Tilley (1814) LIX. Description of a hydro-pneumatic blow-pipe for the use of chemists, enamellers, assayers, and glass-blowers, Philosophical Magazine Series 1 , 43:192, 280-284, DOI: 10.1080/14786441408638024

To link to this article: http://dx.doi.org/10.1080/14786441408638024

电 Published online: 27 Jul 2009.

Submit your article to this journal $₫$

Џll Article views: 2

Q View related articles $₫$ 
ether. I have met with alcohol which produced 1 1-16th more than any other. Does this arise from the heterogeneous principles which they contain more or less, or from the varied proportions of elementary substances of which they are composed, or lastly from a still stronger portion of aroma?

Without attempting to account for these varicties at present, I shall merely say that the alcohols which seem to give most ether are: lst, that produced from perry; $2 \mathrm{~d}$, wine; $3 \mathrm{~d}$, cider. The spirits denominated cherry brandy, rum, geneva, and whisky, are far inferior to those just enumerated in respect of the quantity of ether which they yield.

LIX. Description of a Hydro-pneumatic Blow-pipe for the Use of Chemists, Enamellers, Assayers, and Glass-blowers. By $M r$. John Tilley, of Whitechapel*.

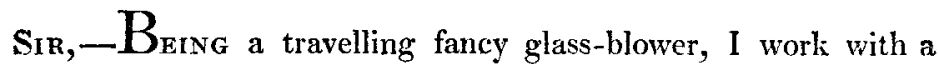
machine which I have contrived for my own use, and which I have been advised, by a great number of respectable gentlemen, to lay before the Society of Arts, \&c. The invention consists of a tin-box, with a partition in it reaching from the top at one cnd to within an inch of the bottom. The vessel is air-tight at this end. It is three parts filled with water. By means of a tube reaching within half an inch of the bottom, I blow into the water at the air-tight end the air rises in bubbles through the water to the top, and forces the water under the partition into the other compartment. The weight of the water acts upon the air which had been blown in, and forces it through a blow-pipe directed to the lamp, and keeps up a continued blast till the air is exhausted. More air may be blown in from time to time, so as to keep the blast regular and continual. It is thus I execute my fancy glass-blowing. The whole apparatus, including lamp and case, weighs only three pounds and a half.

$I$ believe I am the first glass-blower who ever worked with such a machine.

If the Society should think me deserving of any reward, it will be very thankfully received by,

Your obedient humble servant, JoHN TILLEY.

Direct for me at Mr. Thomas Yandall's, bookseller, Old Street Road, near Shoreditch Church.

* Fron Trunsurtions of the Suciety for the Encouragement of Arts, \&c. for 1313 - Fifteen guineas were voted by the Suciety for this communication, aud one of the machines is preserved for pubic inspection in the Society's Lepository.

The 
The apparatus is applicable to the business of cnamellers, jewellers, chemists, and many other arts, and cau be furnished. complete for $2 \ell .12 s .6 d$. made of tinned copper.

Narch 27.1312.

To C. Taylor, M.D. Sec.

\section{Reference to the Engraving of Mr. Tullex's Hydro-pneumatic} Blow-pipe.-Plate IV. Fig. 4, 5, 6, 7, 8.

The utility of the blow-pipe, in the arts, to raise a great heat in a small object, from the flame of a lamp, is too well known to require pointing out. The assay of minerals, the arts of enamelling, jewellery, soldering metal works, but above all the blowing of small articles in glass, are purposes to which it is better adapted than almost any other mode of applying heut. The usual manner of producing a stream of air for blowing glass, is by means of a small pair of double-acting bellows, fixed beneath a table, and worked by the operator's foot; a pipe proceeds from these bellows to the top of the table, and terminates in a small jet, before which a lamp is placed, and the flame blown by the current of air upon the object to be heated. The defects of the bellows are, that the stream of air is not perfectly rejgular, which causes a wavering of the flame, so that it does not fall steadily upon the object which is to be heated. Mr. Tilley's blow-pipe corrects these defects, by using the pressure of a column of water to regulate the stream of air, and the supply is furnished from the mouth of the operator, by blowing through a tube, fig. 4 , C, at a section of this instrument, and fig. 5 shows a perspective view of it in action. $A A$ is a vessel of tinned iron, or copper, about seventeen inches high, five wide, and nine broad; the lid of which opens and shuts on hinges, and supports the lamp $B$, which burns tallow instead of oil. $\mathrm{C}$ is the blowing-pipe, by which the air is thrown into the vessel: this, as shown in the section fig. 4 , has an inclined partition $\mathrm{D}$, which divides it into two chambers, $\mathrm{E}$ and $\mathrm{F}$; but as the partition does not reach to the bottom of the vessel, the two compartments communicate with each other underneath it: that marked $F$ is closed at the top so as to be air-tight ; but the other is only covered by the lid of the vessel, and may therefore be considered as being open to the outward air. The pipe $\mathrm{C}$, fig. 4 , is soldered air-tight, where it passes through the top of the chamber, and descends very near to the bottom of the vessel, deeper than the partition $D$ does, so that its moukh is always immersed beneath the water. The metallic part of the blow-pipe G, which conveys the blast of air to the flame of the lamp, is likewise soldered into the top of the chamber $\mathrm{F}$; it holds a bent glass tube, $a$, 
Phil.Mag.Tol.XLIII./Y.IV.

M.T.Whitfords Mechanical Substitute for Leeches.
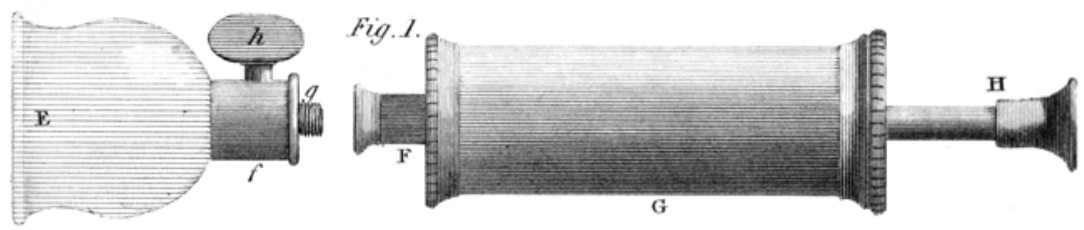

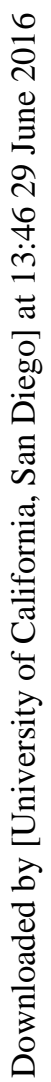

Fig. 2 .
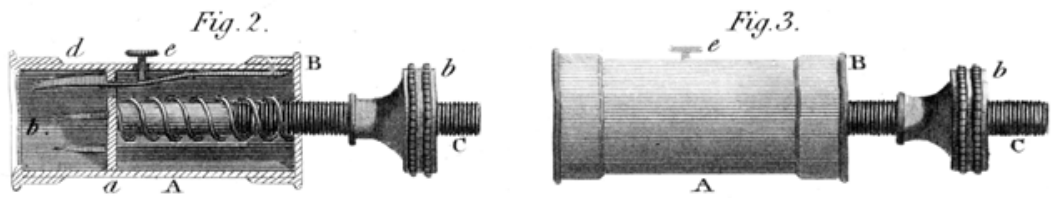

Mr.John Tilley's Hydro Pneumatic Blow-pipe.

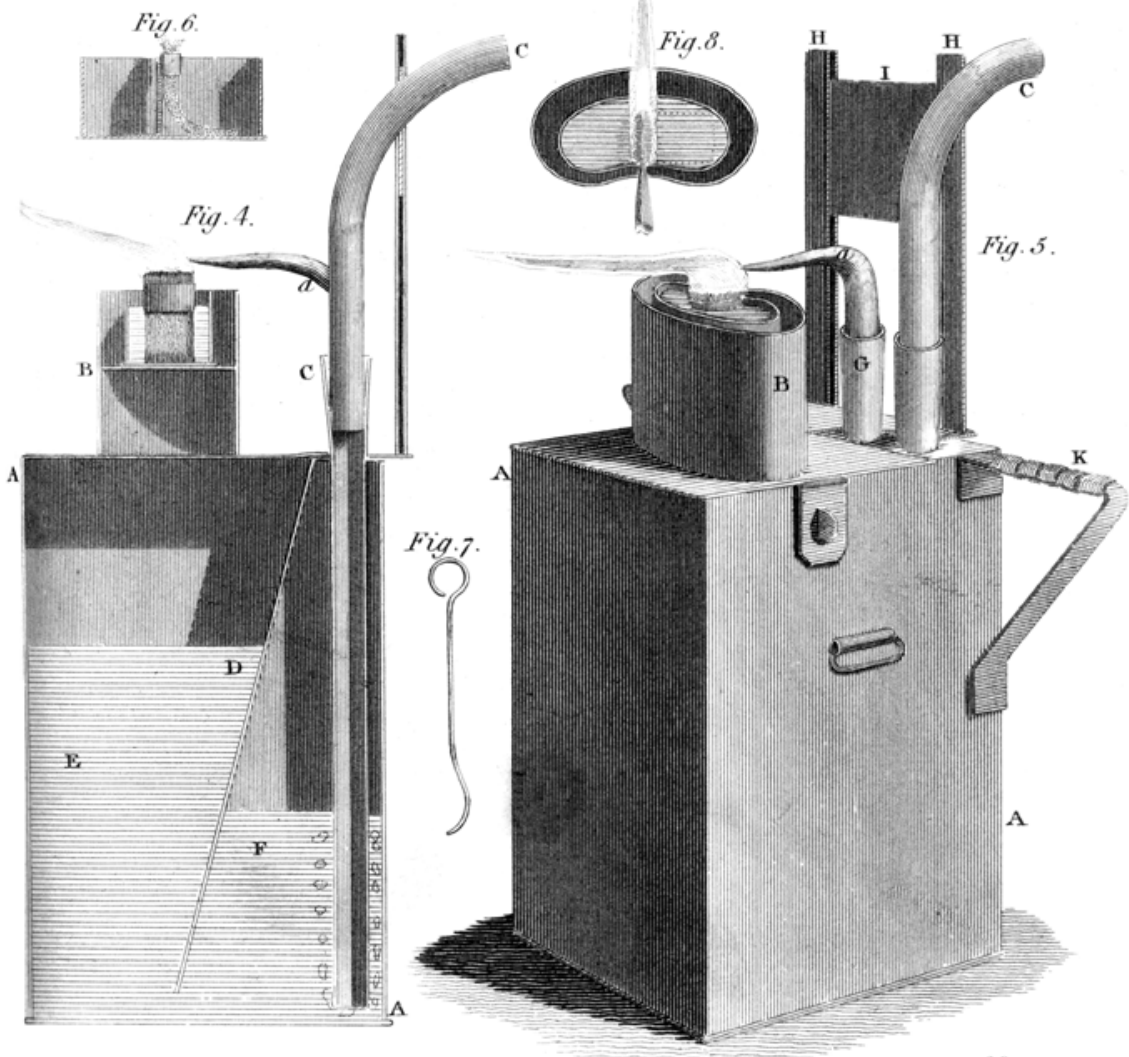


which terminates in a very small and delicate jet, and is fitted air-tight into the tin or copper tube G. Now, by blowing into the tube $\mathrm{C}$, the air is forced out at the bottom of it, and rises in bubbles through the water into the upper part of the chamber $\mathbf{F}$; this displaces a corresponding quantity of water, which passes under the partition $\mathrm{D}$, into the other chamber $\mathrm{E}$, elevating the surface of the column of water, and depressing the other, as shown in the figure; the water endeavouring to return to its original level, causes a constant compressure of the air, and forces it through the jet $a$ into the flame of the lamp. By this means, it is not necessary to blow constantly with the mouth; for, though the air is forced into the receiver at intervals, yet the pressure of the water will expel it in a constant strean, and the operator will not be fatigued by the motion of the foot, necessary in working bellows, nor need even to keep his mouth at the pipe constantly, but merely to blow from time to time, as he finds the stream of air to decrease in its power.

The metal socket which connects the glass tube or blow-pipe $a$ with the vessel $A$, is made conical, and the tube, having a piece of paper first wrapped round it, is bound round with cotton-wick yarn in a conical form, so as to fit the socket tight, and yet permit the tube to be moved in any required direution, to cause the air to act properly upon the flame; and the curved metal tube $C$ is also fixed into the upper part of the tube $C$ in the same manner. HH are the two sides of a tin frame, which is fixed in front of the vessel, and has grooves withinside of them to receive a tin plate $I$, which forms a screen, and can be adjusted in height so as to keep the light of the lamp from the operator's eyes, though he can see the work over the top of it: this screen is held fast by its foot being placed btween the lid of the vessel and the top of the close chamber $F$. $K$ is one of two handles, which support the operator's arms while holding a glass tube or other matter in the flame, and there is another like it at the opposite side of the vessel: these handles are also wrapped round with woollen list or leather, so as to form cushions; and the vessel is steadily fixed upon a chair, bench, \&c. by means of a leather strap buckled to the loops on each side of it, and passing under the chair, \&c.

The lamp is made of tin, is of an elliptical, or rather of a bean or kidney shape, one side being carved inwards; across the centre of it stands a metal wick-holder, having a loop on one sire of it, and which is soldered to its bottom, (see $r$, fig.6.) Throngh this loop the wick of cotton is drawn, and beirig opened both ways, as shown in that figure, and still plainer in fig. 8 , forms a passage in its middle, tlirough which the current of air from the jet $a$ passes as in figs. 4 and 8 , and carries the long pointed flame upon the object to be heated. The lamp, figs. 6 and 8 , 
is filled with tallow, which, melting by the heat, becomes fluid, and burns as well as oil, but with a less offensive smell, and when cold, being solid, is more conveniently carried than oil. This lamp is placed within another vessel marked $R, f(z), 4,5$, and 8 , which supports it at a proper height, learing a space between them all round, to receive any tallow which may run over the edge of the interior vessel or lamp.

In using this blow-pipe, the following observations being attended to, will greatly increase its effect. The iong flat cotton wick of the lamp will be fotund to act better than the usual round cotton wick; but in either case, the flame which it raises will be considerable. The end of the glass pipe $a$ must be just entered into the flame, and the current of air will throw out a cone of flame from the opposite side. If it is well managed, this cone will be distinct and well defined, and extend to a considerable length. Care must be taken, that the stream of air does not strike against any part of the wick, as it would then be disturbed, and the cone split into several parts. (A wire bent at its end, as shown at fig. 7 , is very convenient to smooth the passage through the wick:) the jet of air must be delivered somewhat above the wick; and as, unless the flame was considerable, there would not be sufficient for the stream of air to act upon, for this reason the wick is opened, as shown in fig. 6 , that it may expose the largest surface, and produce the greatest flame; the stream of air from the pipe should be directed through the channel or opening between the wick, so as to produce a cone the most perfect and brilliant. On examining this cone of flame, it appears to be formed of two different colours, the part nearest to the lamp being of a yellowish white, and that beyond of a blue or purple colour.

The subject which is to be heated, is held in the flame at the termination of the yellowish-white flame, where it receives the greatest heat, and is not discoloured by the soot which accompanies the white flame.

Glass tubes are, when applied to this flame, quickly rendered pliable, and may be bent or drawn out into threads or psints, and hermetically sealed; or, by blowing into the other end of the tube, it may be expanded into a small globe, so as to form various small articles at the pleasure of the operator.

In chemistry, mineralogy, and the arts, the blow-pipe is an extremely useful instrument, being capable of throwing such a powerful heat on a small object, as woild be dificult to obtain on a larger quantity of the same substance, in the most powerful furnaces; and with this advantage, that the process is always under the inspection of the operator ; whereas he can unly conjecture what passes in the centre of a umace. 
In using the blow-pipe for experiment, a piece of charcoal is generaily used to support the subject, and held in the flame of the lamp; the charcoal should be of a close compact grain, and properiy burnt ; ior, if it is too litzle carbonized, it will flame like a piece of wood, and obscure the object; and if it is too much burnt, it is so quick'y consumed, and burnt to ashes, that the object is in danger of being lost in it; the charcnal greatly increases the heut, by reverberating the flame, and by heating the object at the opposite side; itself being converted into tuel, and excited by the blast, and thus creates an atmosphere of flame and heated air around it, which prevents the heat being carried off so fast, or the object being so much cooled, as if it should for an instant be moved out of the cone of the flame, from the unsteadiness of the hand, or from accidental currents of air, which would disturb the flame, and cause such a wavering in the point of the cone, as to divert it in some measure from the object. In order to prevent more tallow than is necessary from being consumed, to produce the intended effect, it is convenient to have several lamps with wicks of different thicknesses, viz. one to hold two flat cottolis (such as are used for the Liverpool lamps) of about $1 \frac{1}{4}$ inch broad; another to hold four, and a third to hold six, or as much common wick yarn as is equal to those wicks in bulk : glass jets should also be provided of different sized apertures, to suit the greater or lesser sized wicks and flames, and deliver streams of air upon them proportionately, and their jets should point upwards in a small degree: hogs-lard is also equal or perhaps superior to tallow for the lamp. LX. New Outlines of Chemical Philosophy. By Ez. WaLken,
Esq. of Lynn, Norfolk.

[Continued from p. 105.]

$\mathbf{S}_{\mathrm{IRS}},-\mathbf{I}_{\mathrm{N}}$ a paper published in the Philosophical Magazine, vol. xlii. p. 161, I described an electrometer, which I had contrived for determining the mechanical forces of the two elements that conpose the electric spark. From some experiments made with that instrument it appears that all electrical phrnomena are produced by two distinct powers acting in contrary directions, and with equal energy. At that time I had no other way of determining the equality of those forces, than by inspection; but I have since added some improrements to the instrument, which make it more convenient and correct.

The first improvement consists in cutting a hole through the card, 